\title{
PENGARUH KEDISIPLINAN KERJA, GAYA KEPEMIMPINAN TERHADAP PRODUKTIVITAS KERJA PADA KANTOR DESA TANJUNG HARAPAN
}

\author{
Zufrie \\ Sekolah Tinggi Ilmu Ekonomi (STIE) Labuhan Batu, Sumatera Utara \\ Email : zufrieanhal@ rocketmail.com
}

\begin{abstract}
ABSTRAK
Penelitian ini bertujuan untuk mengetahui pengaruh kedisiplinan kerja, gaya kepemimpinan dalam meningkatkan produtivitas kerja pada kantor Desa Tanjung Harapan. Data yang dikumpulkan dalam penelitian ini adalah penyebaran kuisioner kepada 30 orang responden yang bekerja di Kantor Desa Tanjung Harapan.

Metodeanalisis yang digunakan adalah metode deskriptif kuantitatif dengan pendekatan korelasi ganda dan menggunkan program spssVersi 20. Berdasarkanhasil data persamaan anlisis regresi adalah sebagai berikut: $Y=5.538+0.156 x_{1}+0.564 x_{2}$ berdasarkan pengujian hipotesis menggunakan uji $T$ bahwa kedisiplinan kerja, gaya kepemimpinan berpengaruh positif terhadap produktivitas kerja. Hasil penelitian simultan dengan menggunakan uji $F$ menunjukkan bahwa semua uji variable bebas berpengaruh secara significan terhadap produktivitas kerja. Nilai $R$ Square sebesar 0.481 yang diartikan bahwa pengaruh variabel $X$ (kedisiplinan kerja dan gaya kepemimpinan ) terhadap variabel $Y$ (produktivitas kerja) adalah sebesar 48,1\% sedangkans isanya adalah 51.9\% dipengaruhi oleh variable lain diluar variabel yang diteliti.
\end{abstract}

Kata kunci: Kedisiplinan kerja, Gaya kepemimpinan, Produktivitas kerja.

\section{PENDAHULUAN}

Kinerja merupakan hasil atau prestasi kerja pegawai yangdi nilai dari segi kuantitas berdasarkan standar kerja yang di tentukan oleh pihak organisasi. Semakin tinggi tingkat kedisiplina seorang pegawai oleh arahan dari seorang pimpinanya maka produktivitas organisasai secara keseluruhan akan meningkat. Pegawai dituntut untuk mampu menyelesaikan tugas dan tanggungjawab secara efektif dan efesien. Keberhasilan pegawai dapat diukur melalui kepuasan masyarakat terhadap pelayanannya. 
Terdapat faktor negatif yang dapat menurunkan produktivitas keja pegawai, diantaranya adalah menurunya keinginan pegawai untuk mencapai prestasi kerja, kurangnya ketepatan waktu dalam menyelesaikan pekerjaan sehingga kurang menaati peraturan, pengaruh yang berasal dari lingkungannya,teman sekerja yang juga menurun semangatnya dan tidak ada contoh yang harus dijadikan acuan dalam pencapaian prestasi kerja yang baik. semua itu merupakan sebab menurunnya kinerja pegawai dalam bekerja. Faktor-faktor yanga dapat digunakan untuk meningkatkan Produktivitas Kerja adalah Kedisiplinan Kerja dan Gaya Kepemimpinan.

\section{TINJAUAN PUSTAKA}

Menurut Mangkunegara (2013), disiplin kerja diartikan sebagai pelaksanaan manajemen untuk memperteguh pedoman-pedoman organisasi. Kadang-kadang prilaku pekerja dalam organnsasi menjadi sangat mengganggu ssehingga berdampak dengan kinerja yang menurun. Oleh karna itu, disiplin sangat diperlukan dalam kondisi seperti itu dalam organisasi. masaih banyak karyawan/bawahan yang terlambat, mengabaikan prosedur keselamatan, tidak mngikuti petunjuk yang telah ditentukan atau terlibat masalah dengan rekan kerjanya. Disiplin adalah mematuhi , menhormati, menghargai mengikuti dan taat terhadap peraturan serta norma-norma yang berlaku, baik tertulis maupun tidak tertulis serta siaap menerima sanksi-sanksi apabila melanggar. Maka dari itu setiap perusahaan/organisaasi diharapkan memiliki berbagai ketentuan yang harus ditaati dan standard yang harus dipenuhi oleh anggotanya yang merupakan tidakan manajemen untuk mendorong para anggotanya untuk memenuhi tututan tersebut .

Untuk memahami gaya kepemimpinan terlebih dahulu kita ketahui definisi Kepemimpinan Menurut House dalam Gary Yuki,(2009:4) mengatakan bahwa Kepemimpinan adalah kemampuan individu untuk mempengaruhi, memotivasi, dan membuat orang lain mampu memberikan kontribusinya demi efektivitas dan Gaya Kepemimpinan. keberhasilan organisasi. Jadi dari pendapat House dapat dikatakan bahwa kepemimpinan merupakan cara mempengaruhi dan memotivasi orang lain agar orang tersebut mau berkontribusi untuk keberhasilan organisasi.

Menurut Hasibuan (2008), kepemimpinan adalah : "Proses mempengararuhi orang lain untuk memahami dan setuju tentang apa yang akan di kerjakan dan bagaimana tugas itu dapat 
dilakukan secara efektif,dan proses memfasilitasi usaha individu dan kelompok untuk mencapai tujuan bersama “. Sedangkan George R Terry (Miftha Thoha,2010:5) mengartikan bahwa kepemimpinan adalah aktivitas untuk mempengaruhi orang-orang supaya diarahkan mencapai tujuan organisasai. kepemimpinan meliputi proses mempengaruhi dalam menentukan tujuan organisasai, memotivasi prilaku pengikut untuk mencapai tujuan, mempengaruhi untuk memperbaiki kelompok dan budayanya.

Menurut Tohardi yang dikutip oleh Sutrisno (2011:100) mengungkapkan bahwa produktivitas kerja merupkan sikap mental yang selalu mencari perbaikan terhadap apa yang telah ada, suatu keyakinan bahwa seseorang dapat melakukan pekerjaan yang lebih baik hari ini daripada hari kemarin, dan hari esok lebih baik daripada hari ini.

Menurut Tohardi yang didukung oleh Ravianto yang dikutip oleh Sutrisno (2011:100) yang menyatakan produktivitas kerja pada dasarnya mencakup sikap mental yang selalau mempunyai pandangan bahwa kehidupan hari ini harus lebih baik daripada kemarin .sikap ini mendorong agar seseorang tidak merasa cepat puas ,akan tetapi harus mengembangkan diri dan meningkatkan kemampuan kerja dengan cara mencari perbaikan-perbaikan dan peningkatan.

\section{HASIL DAN PEMBAHASAN}

\section{Hasil Analisis Uji Asumsi Klasik (Uji Normalitas , Uji Multikoliniearitas, Uji Heteroskedastisitas}

Aalisis Uji Asumsi Klasik Untuk mengetahui hasil uji asumsi kalsik pada penelitian ini sebagai berikut:

\section{a.Pengujian Asumsi Normalitas}

Modsel regresi yang memenuhi asumsi Normalitas yakni apabila nilai residu Asympy.sig(2tailed) lebih besar dari 0,05 maka dapat dinyatakan Dalam penelitian ini sesata statistic berdistribusi normal dan jika Asympy.sig(2-tailed) lebih dari 0,05 maka didistribusikan tidak normal. Karena nilai residual Asympy.sig(2-tailed) pada gambar: 
P-ISSN : 2477-6092

E-ISSN : 2620-3391

http://ojs.stie-labuhanbatu.ac.id/index.php/

\section{JURNAL ECOBISMA}

Vol.6 No.2 2019

Gambar 4.2

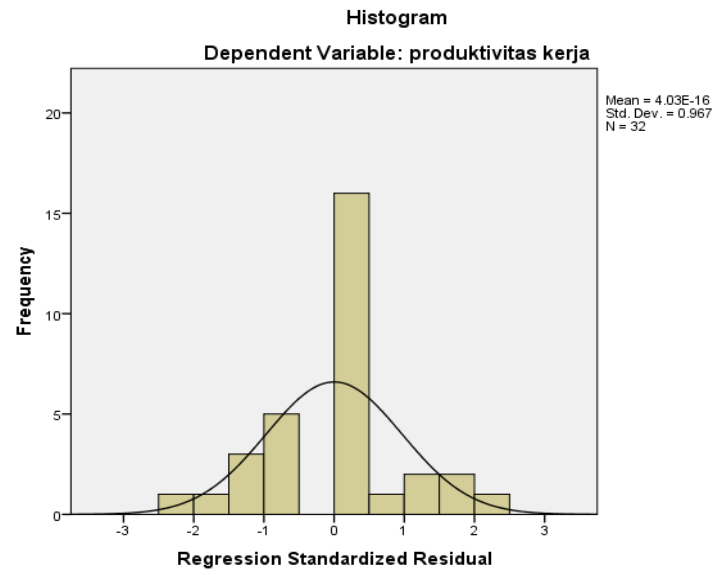

Sumber: data diolah 2018

Gambar 4.3

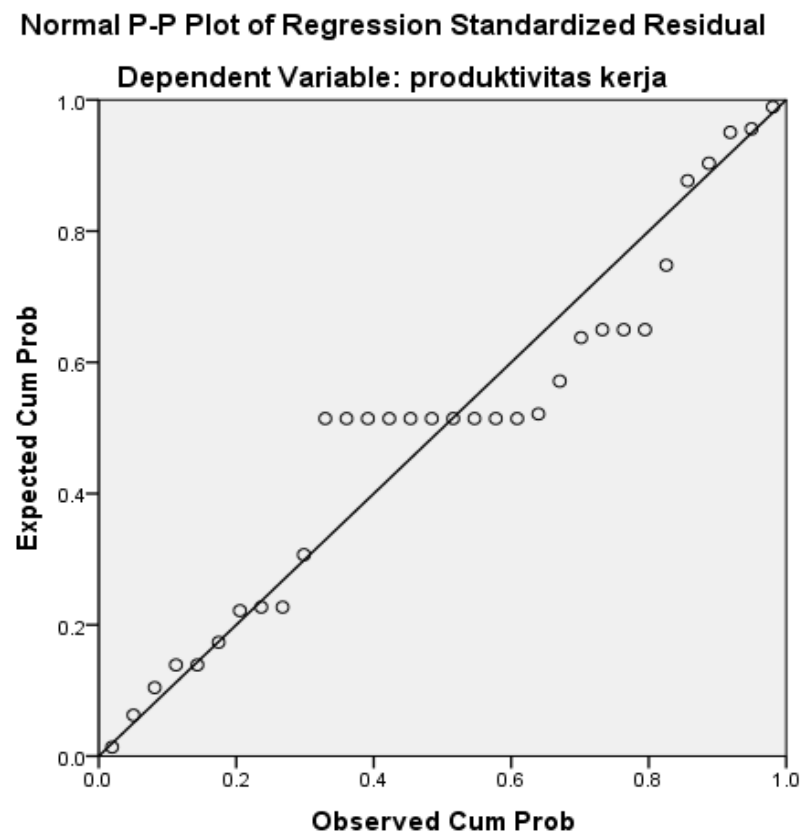

Sumber: data diolah 2018 
b. uji multikoleneritas

multikolenetitas adalah kondisi terdapatnya linear atau kolerasi yang tinggi antara masingmasing variabel independen dalam model regresi. perhitungan uji independen antar variabel bebas dapat dilihat dari hasil analisis collinnearity statistik. Multikoleneritas terjadi apabila (1) nilai tolerance $<0,10$ (2) variance inflation factor(VIF>10). Hasil pengujuan untuk uji multikolinearitas ditampilkan pada tabel berikut:

\begin{tabular}{|c|l|c|c|}
\hline \multicolumn{2}{|c|}{ Model } & \multicolumn{2}{c|}{ Collinearity Statistics } \\
\cline { 2 - 4 } \multicolumn{1}{|c|}{1} & Tolerance & VIF \\
\hline \multirow{2}{*}{1} & (Constant) & & 1.709 \\
\cline { 2 - 4 } & kedisiplinan kerja & .585 & 1.709 \\
\cline { 2 - 4 } & gaya kepemimpinan & .585 & \\
\hline
\end{tabular}

Sumber : data diolah 2018

Dari tabel diatas memperhatikan nilai tolerance untuk semua factor lebih besar dari 0,10 . Dan nilai VIF lebih kecil dari 10.Hal ini berarti tidak ada problem multikolenerias atau kolerasi yang tinggi antar factor yang terbentuk.

\section{c. Uji Heteroskedasitas}

Tujuan dari uji Heteroskedasitas ini adalah untuk menguji apakah dalam model regresi terjadi ketidaksamaan varience dari residual satu pengamatan ke pengamatan lain tetap.model regresi yang baik adalah tidak menglami gejala heteroskedaritas, hasil pengujian heteroskedaritas dengan menggunakan metode gambar dapat dilihat pada gambar berikut: 


\section{JURNAL ECOBISMA Vol.6 No.2 2019}

Gambar 4.3

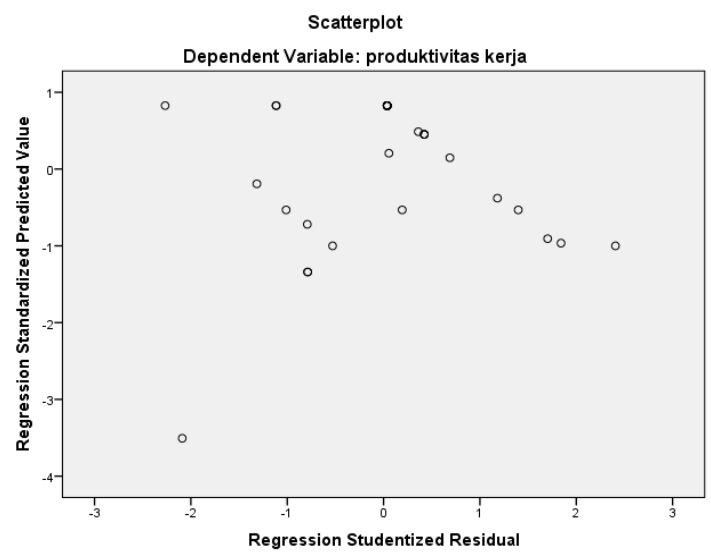

sumber: data diolah 2018

Berdasarkan gambar diatas terlihat bahwa titik-titik menyebar diatas dan dibawah anggka nol dengan demikian dapat disimpulkan bahwa persamaan regresi hipotesis penelitian ini terbebas dari heteroskedaritas.

\section{Analisis Regresi Linear Berganda}

Analisis Regresi Linier Berganda

Model regresi berganda adalah model yang dapat digunakan untuk menganalisis pengaruh dari beberapa variabel independen terhadap suatu variabel dependen

Table 4.8 Regresi Linear Berganda

\begin{tabular}{|l|c|}
\hline \multicolumn{1}{|c|}{ Model } & B \\
\hline (constant) & 5.538 \\
\hline Kedisilinan kerja & .169 \\
\hline Gaya kepemimpinan & .564 \\
\hline
\end{tabular}

Sumber data : Data SPSS (2018) 
P-ISSN : 2477-6092

E-ISSN : 2620-3391

http://ojs.stie-labuhanbatu.ac.id/index.php/
JURNAL ECOBISMA

Vol.6 No.2 2019

Hasil persamaan regresi berganda yaitu :

$\mathrm{Y}=5.538+0.169 \mathrm{x}_{1}+0.564 \mathrm{x}_{2}$

Hasil persamaan regresi berganda tersebut di atas memberikan pengertian bahwa:

a. untuk variabel kedisiplinan kerja $\mathrm{X}_{1}$ koefisien regresinya adalah positif, hal ini dapat diartikan apabila kedisiplinan kerja semaikin baik, maka produktivitas kerja akan semakin meningkat.

b. Untuk variabel Gaya kepemimpinan $\mathrm{X}_{2}$ koefisien regresinya adalah posif, hal ini dapat diartikan apabila Gaya Kepemimpinan dilakukan dengan baik, maka produktivitas kerja akan semakin meningkat.

\section{a. Uji F}

uji $\mathrm{F}$ pada dasarnya menunjukkan apakah semua variabel independen yang dimasukkan dalam model mempunyai pengaruh secara simultan atau bersama-sama terhadap variabel dependen. hasil perhitungan menggunakan spss V20 disajikan pada tabel sebagai berikut:

Table 4.9 Uji F

\begin{tabular}{|l|l|l|l|l|c|c|}
\hline \multicolumn{2}{|c|}{ Model } & Sum of Squares & Df & Mean Square & F & Sig. \\
\hline \multirow{2}{*}{1} & Regression & 85.526 & 2 & 42.763 & 13.429 & $.000^{\mathrm{b}}$ \\
\cline { 2 - 8 } & Residual & 92.349 & 29 & 3.184 & & \\
\cline { 2 - 7 } & Total & 177.875 & 31 & & & \\
\hline
\end{tabular}

Sumber: data diolah 2018

F tabel $=\mathrm{k}: \mathrm{n}-\mathrm{k}$

$=2: 32-2$

$=3,32$ 
Berdasakan tabel diatas terlihat bahwa nilai $\mathrm{F}$ hitung 13,429> 3,32 dan nilai signifikan $0,000<0,005$, ini menunjukkan bahwasecara simultan variabel independen berpengaruh positif dan sifnifikan terhadap variabel dependen.

b. Uji T

Uji T dilakukan untuk menguji secara parsial apakah variabel independen yang terdiri dari kedisiplinan kerja dan gaya kepemimpinan secara parsial mempunyai yang signifikan terhadap variaabel dependan . haji Uji T dapat dilihat pada tabel berikut:

tabel: 4.10. Uji T

\begin{tabular}{|c|c|c|c|c|c|c|}
\hline \multicolumn{2}{|c|}{ Model } & \multicolumn{2}{|c|}{ Unstandardized Coefficients } & $\begin{array}{c}\text { Standardized } \\
\text { Coefficients }\end{array}$ & Sig. \\
\cline { 2 - 7 } & \multicolumn{2}{|c|}{ B } & Std. Error & Beta & \\
\hline \multirow{3}{*}{1} & (Constant) & 5.538 & 2.621 & & 2.113 & .043 \\
\cline { 2 - 7 } & kedisiplinan kerja & .156 & .169 & .161 & .922 & .364 \\
\cline { 2 - 7 } & gaya kepemimpinan & .564 & .171 & .578 & 3.307 & .003 \\
\hline
\end{tabular}

Sumber : data diolah mengguankan spss V20 (2018)

Berdsarkan tabel diatas maka dapat dilihat pengujian masing-masing variabel independen yaitu sebagai berikut:

a. kedisiplinan kerja berpengaruh positif dan signifikan terhadap produktivitas kerja, hal ini dapat dilihat dari,nilai $\mathrm{t}$ hitung >t tabel 2.113>2,045 dengan nilai signifikan lebih kecil dari 0,05 $(0,43<0,05)$, sehingga keputusan yang diambil adalah ha diterima dan ho ditolak

b, gaya kepemimpinan berpengaruh positif dan signifikan produktivitas kerja . hal ini terlihat dari, nilai t hitung > t tabel $(3,307>2,045$ dengan nilai signifikan lebuih kecil dari $0,05(0,43<0,05)$, sehingga keputusan yang diambil adalah ha ditrima dan ho ditolak. 


\section{c. koefisien Determinan}

Koefisien determinan $\left(\mathrm{R}^{2}\right)$ pada intinya mengukur seberapa jauh kemampuan variabel tergantung dalam mempengaruhi variabel dependen. Nilai koefisien determinasi adalah antara nol dan satu .nilai koefisien determinasi dapat dilihat pada tabel dibawah ini!

\section{Tabel:4.11}

\section{Determinasi}

\begin{tabular}{|c|c|c|c|c|}
\hline Model & $\mathrm{R}$ & R Square & Adjusted R Square & Std. Error of the Estimate \\
\hline 1 & $.693^{\mathrm{a}}$ & .481 & .445 & 1.78450 \\
\hline
\end{tabular}

Sumber: data diolah dengan spss v20(2018)

Hasil output spss model Summary besarnya R square adalah 0,481. Hal ini berarti 48,1\% variabel independen, dan sisanya sebesar 51,9\% dipengaruhi oleh faktor lain yang tidak diteliti yang dapat mempengaruhi variabel produiktivitas kerja.

\section{Pembahasan penelitian}

Berikut ini hasil penelitian yang akan dibahas secara rinci sebagai berikut:

1. Secara parsial, variabel kedisiplinan kerja berpengaruh positif dan signifikan terhada produktivitas kerja pegawai, kemajuan suatu organisasi sangat dipengaruhi oleh produktivitas kerja pegawainya agar mencapai target yang ingin dicapai.

Koefisien regresi kedisiplinan kerja menunjukkan hubungan positif terhadap produktifitas kerja pada kantor desa torgaamba dengan nilai koefisien 0,156. Berarti peningkatan setiap kedisiplinan kerja sebesar 0,156 akan meningkatkan produktivitas kerja sebesar 0,156 
Maka apabila kedisiplinan kerja meningkat maka produktivitas kerja karyawan juga cenderung lebih menigkat dalam memberikan pelayana pada masyarakat.

2. Secara parsial, gaya kepemimpinan berpengaruh positif dan signifikan .gaya kepemimpinan sangat mempengaruhi produktivitas kerja, gaya kepemimpinan yang baik akan membuat para bawahan / pegawai akan lebih nyaman dan terkontrol dalam melaksanakan segala tugas yang di emban, sehingga menghasilkan produktivitas kerja yang baik. koefisien gaya kepemimpinan menunjukkanhubungan positif terhadap produktivitas kerja pada kantor Desa Tanjung Harapan, dengan nilai koefisien 0,564. Berarti peningkatan setiap gaya kepemimpinan sebesar 0,564 akan meningkatkan produktivitas sebesar 0,564. Maka dapat disimpulkan bahwa semakin tepat gaya kepemimpinan suatu pemimpin dalam sebuah organisasi maka akan baik pula hasil produktivitas kerja bawahan nya.

3. Secara simultan, variabel kedisiplinan kerja ,gaya kepemimpinan berpengaruh positif dan signifikan terhadap produktivitas kerja pada kantor Desa Tanjung Harapan dari data yang dibuat pada $\mathrm{F}$ tabel dan F hitung dilihat bahwa $\mathrm{F}$ hitung 13,429 > F tabel 3,32 yang artinya variabel independen secara serempak berpengaruh terhadap variabel dependen dan nilai signifikannya adalah $0,000<0,05$. Peningkatan produktivitas kerja pada setiap organisasi/perusahaan akan sangat mempengaruhi keberhasilan pada setiap visi dan misi suatu organisasi tersebut. Dan perkembangan itu terjadi apabila kepemimpinan dan disiplin yang di terapkan pada suatu prusahaan /organisasi itu secara tepat. Tidak hanya kepemimpinan saja tapi kedisiplian juga penting sebagai wujud kesadaran diri dalam tanggungjawab kerja guna meningkatkan dan menghasilkan produktivitas kerja yang baik sehingga tecapai tujuan sebuah organisasi.

\section{KESIMPULAN}

Berdasarkan hasil penelitian yang telah di lakukan dapat diketahui bahwa faktor yang paling mempengaruhi produktivitas kerja adalah gaya kepemimpinan, hal ini ditunjukkan dengan 
nilai satndradized coeifisien yang tersebar, yaitu 0,578 kondisi ini terjadi karena gaya kepemimpinan merupakan pendorong seorang pegawai untuk bekerja lebih baik.

Gaya kepemimpinan berpengaruh secara positif dan signifikan terhadap kinerja pegawai , hal in terjadi secara signifikan sebesar 0,000 dimanan angka tersebut lebih kecil dari 0,05, semakin baik gaya kepemimpinan yang dilakukan maka semakin baik produktivitas kerja pegawai yang di hasilkan, sesuai dengan H1: gaya kepemimpinan mempunyai pengaruh positif dan signifikan terhadap produktivitas kerja seorang pegawai,

Kedisiplinan kerja berpengaruh positif terhadap kinerja pegawai. Hal ini dibuktikan dengan signifikan sebesar 0,922 diman angka tersebut lebih kecil dari 0,05. Artinya apabila kedisiplinan kerja semkin baik , maka produktivitas kerja akan meningkat . sesuai deng H1: kedisiplinan kerja memiliki pengaruh positif dan signifikan terhadap produktivitas pegawai. Nilai koefisien determinasi sebesar 0,693, artinya 69,3\% produktivitas kerja pada kantor desa Tanjung Harapan dipengaruhi oleh variabel kedisiplinan kerja dan gaya kepemimpinan, sedangkan selebihnya 30,7\% dipengaruhi oleh variabel

\section{DAFTAR PUSTAKA}

Akdon dan Riduwan,2007.Rumus dan Data Dalam Analisis Statistika cetakan ke-2. Bandung. Alfabeta.

Agung Setiawan ,2013. Dalam jurnal berjudul "Pengaruh Disiplin Kerja dan Motivasi Terhadap Kinerja Pegawai Pada Rumah Sakit Umum Daerah Kanjuruhan Malang”.Jurnal Ilmu Manajemen | Volume 1 Nomor 4 Juli 2013.

Harlie,M.2010.Pengaruh Disiplin Kerja,Motivasi Dan Pengembangan Karier Terhadap Kinerja Pegawai Negeri Sipil Pada Pemerintah Kabupaten Tabalong Di Tanjung Kalimantan Selatan.

Hasibuan,Malayu,S.P.200. Manajemen Sumber Daya Manusia.Jakarta: Cetakan 9. PT.Bumi Aksara.

Juliana Harahap,2014. Dalam Skripsi Yang Berjudul "Pengaruh Gaya Kepemimpinan Dan Disiplin Kerja Terhadap Kinerja Pegawai Di Dinas Kependudukan Dan Pencatatan Sipil Kabupaten Labuhanbatu Selatan”.skripsi ilmu manajemen .Yayasan Universitas Labuhan Batu. 


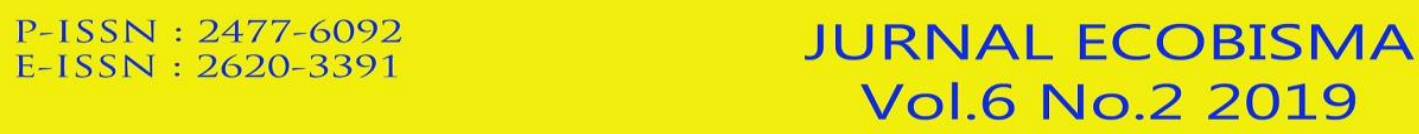

Kartini,kartono. 2005.Pemimpin dan Kepemimpinan .Jakarta : Rajawali Pers .

Malayu,Hasibuan,S.P. 2007. MANAJEMEN Sumber Daya Manusia.Jakarta : $\quad$ Cetakan 9. PT.Bumi Aksara. 